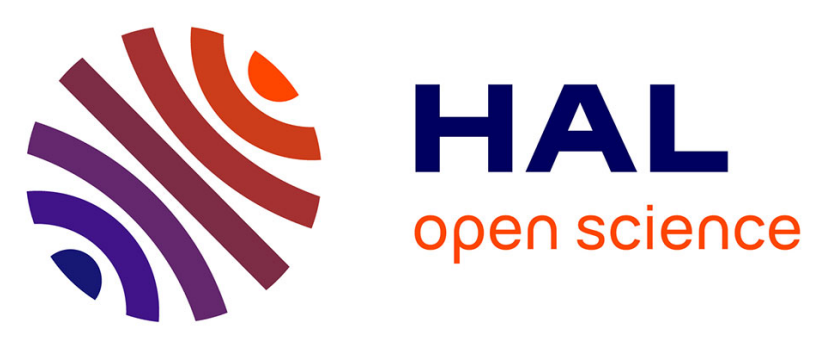

\title{
Hierarchical Self-Assembly of Polyoxometalate-Based Organo Palladium(II) Metallomacrocycles via Electrostatic Interactions
}

Raphaël Salles, Benjamin Abécassis, Etienne Derat, Dalil Brouri, Aurélie Bernard, Qichun Zhang, Anna Proust, Christophe Desmarets, Guillaume Izzet

\section{To cite this version:}

Raphaël Salles, Benjamin Abécassis, Etienne Derat, Dalil Brouri, Aurélie Bernard, et al.. Hierarchical Self-Assembly of Polyoxometalate-Based Organo Palladium(II) Metallomacrocycles via Electrostatic Interactions. Inorganic Chemistry, 2020, 59 (4), pp.2458-2463. 10.1021/acs.inorgchem.9b03333 . hal-02887768

\section{HAL Id: hal-02887768 \\ https: / hal.sorbonne-universite.fr/hal-02887768}

Submitted on 9 Nov 2020

HAL is a multi-disciplinary open access archive for the deposit and dissemination of scientific research documents, whether they are published or not. The documents may come from teaching and research institutions in France or abroad, or from public or private research centers.
L'archive ouverte pluridisciplinaire HAL, est destinée au dépôt et à la diffusion de documents scientifiques de niveau recherche, publiés ou non, émanant des établissements d'enseignement et de recherche français ou étrangers, des laboratoires publics ou privés. 
Hierarchical Self-Assembly of polyoxometalate-based organo Palladium(II) Metallomacrocycles via Electrostatic Interactions.

\author{
R. Salles, B. Abécassis, E. Derat, D. Brouri, A. Bernard, Q. Zhang, A. Proust, C. Desmarets, G. \\ Izzet*
}

\title{
Introduction
}

Individual molecular building blocks that can self assemble into different complex molecular architectures with proper molecular organization are currently drawing a vigorous attention. ${ }^{1-8}$ Indeed the path that goes from discrete molecules to nanostructured macro or mesoscopic assemblies is a cutting-edge challenge for present and future chemistry. ${ }^{9-11}$ The way has already been partially paved by research on coordination-driven self-assembly ${ }^{12}$ although supramolecular architectures regulated by redox-active units have been considerably less investigated. $^{13-15}$ Polyoxometalates (POMs) are anionic oxo-clusters that display unique redox properties and are thoroughly investigated for their promising technological applications. ${ }^{16-18}$ They can be functionalized into organic-inorganic hybrids though the covalent grafting of organometallic fragment onto the polyoxometalate framework. ${ }^{19-20}$ Thanks to their nanoscale size, their tunable redox properties, and their sensitivity to various types of interactions, hybrid POMs are promising building blocks for the elaboration of complex nanostructured molecular architectures. For instance, hybrid POMs displaying remote coordination sites can self-assemble in metallomacrocycles upon metal coordination where positive and negative charges can further be associated. We previously developed such an approach by connecting ditopic Keggin types and Dawson type hybrids donors to linear metal acceptors. ${ }^{21-22}$ However this system afforded mixtures of triangle and square shape secondary building units leading to defects in the stacking of the metallomacrocycles, owing to the mismatch between these two species.

This drove us in investigating the self-assembly of similar hybrid ditopic donors with $90^{\circ}$ degrees metal acceptor, since a unique type of square-shape metallomacrocycle (containing 2 hybrid POMs and 2 metal acceptors) should be formed using this strategy. We herein report the self-assembly of bis silylated Keggin-based building units in the presence of $\left[\mathrm{Pd}(\mathrm{eda})(\mathrm{MeCN})_{2}\right]\left(\mathrm{BF}_{4}\right)_{2}$, a well-known metal acceptor displaying two orthogonal accessible coordination sites imposed by the ethylenediamine (eda) ligand. We show that in a highly dissociating solvent these hybrid POMs self-assemble into a unique discrete supramolecular architecture that can further self-aggregate into different hierarchical self-assemblies according to the solvent composition.

\section{Design and synthesis of the POM-based elementary building unit}

We previously showed that the metal driven self-assembly of Keggin type hybrids led to more stable assembly than Dawson-type analogues probably owing to a lower charge and hence a lower entropy contribution of the resulting self-assembly. ${ }^{23-24}$ Furthermore Keggin type POMs display a pseudo axial symmetry (not present in the Dawson analogues) that should lead to a the formation of a unique pseudo $\mathrm{D}_{2 h}$ supramolecular assembly upon metal coordination in which the aromatic rings of the organic linker should be chemically equivalent and therefore, give a single set of NMR signals. Therefore, we focused on the Keggin-type POM hybrid $\left[\mathrm{PW}_{11} \mathrm{O}_{39}\left\{\mathrm{Si}_{2} \mathrm{OC}_{26} \mathrm{H}_{16} \mathrm{~N}_{2}\right\}\right]^{3-}$ named $\mathbf{K}_{\mathrm{Si}}[\mathbf{p y r}]$. This hybrid contains two pyridine functions connected to a bis-siloxane organic tether grafted on the lacunary site of the monovacant POM $\left[\mathrm{PW}_{11} \mathrm{O}_{39}\right]^{7-}$ (Figure 1). A Sonogashira cross-coupling reaction, as previously developed in the group (ref ?), was used to attach the pyridine function to the parent hybrid platform containing two iodo-aryl groups. The hybrid $\mathbf{K}_{\mathrm{Si}}[\mathbf{p y r}]$ was isolated as a tetrabutylammonium (TBA) salt and characterized by ${ }^{1} \mathrm{H}$ NMR, mass spectrometry, and chemical analysis (Figures $1 \& \mathrm{~S} 1$ ). 


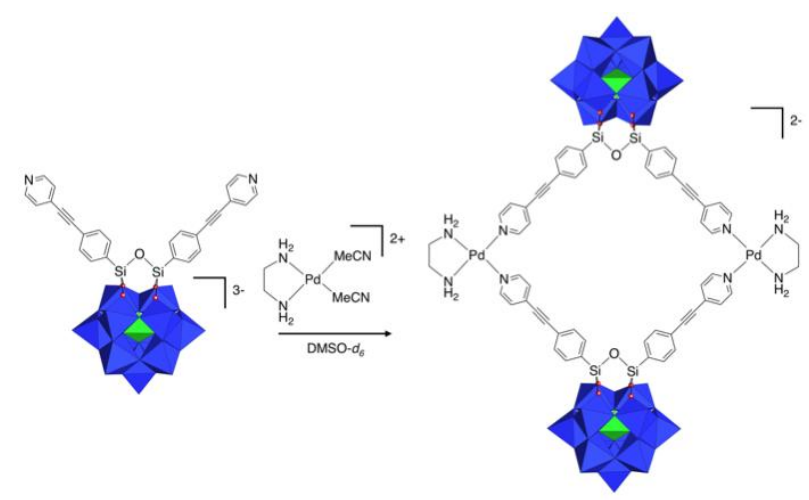

Figure 1. Structure of $\mathbf{K}_{\text {Si }}[\mathbf{p y r}]$ and its resulting organopalladium(II) metallomacrocycle.

\section{Synthesis of the discrete supramolecular assembly}

The addition of $\left[\mathrm{Pd}(\mathrm{eda})(\mathrm{MeCN})_{2}\right]\left(\mathrm{BF}_{4}\right)_{2}$ to a solution of the POM-based building block $\mathbf{K}_{\mathrm{Si}}[\mathbf{p y r}](5 \mathrm{mM})$ in DMSO- $d_{6}$ was followed by ${ }^{1} \mathrm{H}$ NMR spectroscopy. The monitoring of the reaction shows the progressive formation of a unique set of new signals and the concomitant disappearance of those of the starting POM-based building block. The reaction is complete after the addition of 1.2 equivalents of $\left[\mathrm{Pd}(\mathrm{eda})(\mathrm{MeCN})_{2}\right]\left(\mathrm{BF}_{4}\right)_{2}$ (Figure $2 \& \mathrm{~S} 2$ ), which suggests that the resulting species presents a 1:1 stoichiometry between the POM and the Pd unit while a minor excess of $\mathrm{Pd}$ species, observed at $c a .5 .5 \mathrm{ppm}$ is necessary for the reaction of $\mathbf{K}_{\mathrm{Si}}$ [pyr] to be complete. Interestingly, chemical shifts of the new species at intermediate $\left[\mathrm{Pd}(\mathrm{eda})(\mathrm{MeCN})_{2}\right]\left(\mathrm{BF}_{4}\right)_{2}$ concentration are the same as those of the final species which was not the case in the previous POM-Pd and POM-Co systems using linear metal acceptors. In these last systems we observed the prior formation of a molecular dimer with a POM:metal (2:1) stoichiometry at intermediate concentration of the metal linker, which evolved into the metallomacrocycles in the presence of 1 equiv. of metal linker. ${ }^{21,24} \mathrm{We}$ concluded that the formation of the cyclic assembly in such system was not noncooperative, probably owing to a high entropic cost due to the global gathering of the associated counter-ions. In the present case the targeted assembly spontaneously forms without the intermediate dimer at POM:Pd 2:1 stoichiometry.

We also performed DOSY NMR to evaluate the diffusion coefficients of the starting hybrid POM and after the addition of 1.2 equiv. of $\left[\mathrm{Pd}(\mathrm{eda})(\mathrm{MeCN})_{2}\right]\left(\mathrm{BF}_{4}\right)_{2}$. In both cases the set of aromatic signals of the hybrid POM decays similarly according to the pulsed-field gradient strengths with a unique diffusion coefficient : $\mathrm{D}_{1}=1.2 \times 10^{-9} \mathrm{~m}^{2} \cdot \mathrm{s}^{-1}$ for the starting hybrid and $\mathrm{D}_{2}=7.7 \times 10^{-10} \mathrm{~m}^{2} \cdot \mathrm{s}^{-1}$ for the supramolecular species (Figure 2 and S3-S4). Furthermore, in the last case, the major peak at $5.6 \mathrm{ppm}$, corresponding to the eda ligand, displays a diffusion coefficient close to $\mathrm{D}_{2}$, suggesting the participation of the $\mathrm{Pd}(\mathrm{eda})$ moieties in the supramolecular assembly (note that the slight discrepancy in the diffusion coefficient of the aromatic signals and those of the ethylenediamine moieties probably arises from some exchange of the Pd(eda) moieties in the supramolecular assembly and in the minor unbounded forms at the time scale of the DOSY). By contrast the minor peaks at 5.55 and $5.50 \mathrm{ppm}$ displays considerably higher diffusion coefficient, that can not be properly evaluated with a unique diffusion coefficient (Figure S5), that we attribute to unbounded $\mathrm{Pd}(\mathrm{eda})$ species in equilibrium with the supramolecular assembly. 


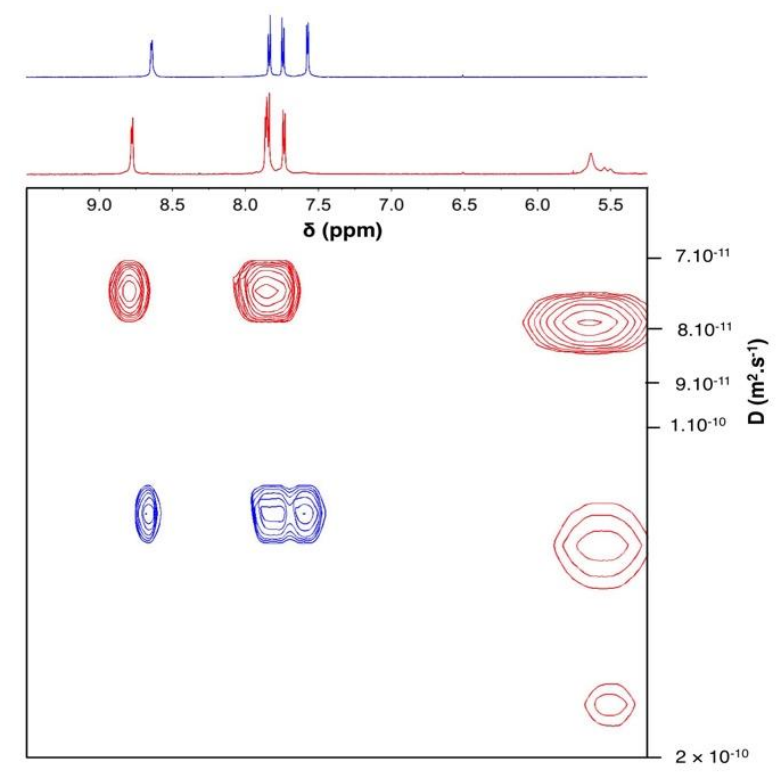

Figure 2: ${ }^{1} \mathrm{H}$ NMR $\left(600 \mathrm{MHz}, \mathrm{DMSO}-d_{6}\right)$ with corresponding DOSY ${ }^{1} \mathrm{H}$ NMR of $\mathbf{K}_{\mathrm{Si}}[\mathbf{p y r}](5 \mathrm{mM}$, bue) and its resulting supramolecular assembly in the presence of 1.2 equiv. $\left[\mathrm{Pd}(\mathrm{eda})(\mathrm{MeCN})_{2}\right]\left(\mathrm{BF}_{4}\right)_{2}$ (red).

We previously evaluated the ratio in the diffusion coefficient between a given assembly and the starting POM hybrid platform on a series of hybrid POM assemblies of different nuclearities (dimer, trimer and tetramer). We found that the diffusion coefficient ratio between a dimer and the starting hybrid POM was about 1.7 , a value that is rather close to $D_{1} / D_{2}=1.6$, which suggests the formation of a dimeric macrocyclic species.

\section{Structural characterizaion of the metallomacrocycle: molecular modeling \& SAXS analysis}

To gain insight into the structure of the cyclic oligomer, optimization of geometries of the square shape supramolecular species was performed by energy minimization with a DFTB method owing to the large size of the system. More specifically, we build the putative $\left.\mathbf{K}_{\mathrm{Si}}[\mathbf{p y r}]_{2} \cdot \mathbf{P d}(\mathbf{P d a})\right]_{2}$ system and its geometries was optimized using the XTB program developed by Grimme et al. ${ }^{25}$ using the last generation of semi-empirical tight-binding method, namely GFN2-xTB. ${ }^{26}$ To ensure that the geometry found is a stable conformer, simulated annealing was performed after a first geometry optimization, and then the most stable conformer was re-optimized. This computational structure can be seen in Figures 3 and S6. One can notice its relative flatness since the dihedral angle between the four units (defined by the two Pd atoms and the two oxygens of bridging the silicon atoms) is $1.97^{\circ}$ (Table S1). The two POM units are separated by a distance of $14.70 \AA$ while the distance between the two Pd atoms is $24.03 \AA$. The two angles Pd-POM-Pd are found to be $116.91^{\circ}$ and $117.27^{\circ}$, closed to the ideal $120^{\circ}$. 


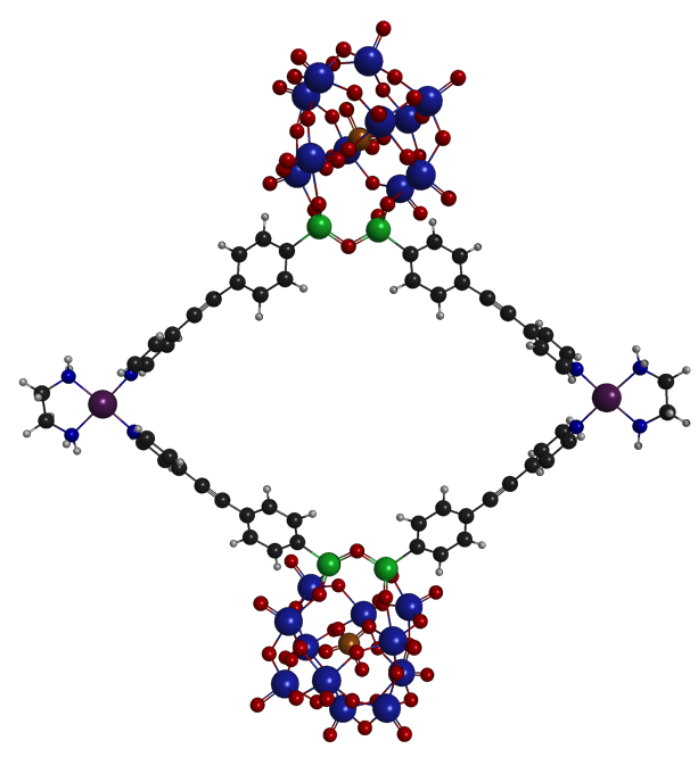

Figure 3. Optimized structure of $\mathbf{K}_{\mathrm{Si}}[\mathbf{p y r}]_{2 \cdot}[\operatorname{Pd}(\mathbf{e d a})]_{2}$.

We also performed SAXS to complete the analysis of the supramolecular system. This technique is indeed well suited to characterize the structure of molecular assemblies and aggregates with sizes that range from 1 to $100 \mathrm{~nm}$ that we and others have successfully used to characterize the formation of POM-based self-assemblies. ${ }^{27-29}$ A significant SAXS signal is visible for the molecular building block $\mathbf{K}_{\mathrm{Si}}[\mathbf{p y r}]$ in DMSO- $d_{6}$ solution, consistent with well-dispersed nanometric objects. As previously observed with hybrid POMs, electrostatic repulsion between the charged species results in a small decrease in intensity at small wave vectors. The SAXS diagram of the supramolecular assemblies displays oscillations in intensity that are characteristic of a distance larger than the POM dimension (Figure 4). We also observed that in DMSO- $d_{6}$ the POM-Pd supramolecular systems evolved under the beam preventing scan accumulation. If we ignore the decrease in intensity caused by the electrostatic interactions, we can notice that the maximum intensity increases by a factor of $c a$. 2 between the POM-Pd supramolecular assembly and the parent $\mathbf{K}_{\mathrm{Si}}[\mathbf{p y r}]$ building unit, in agreement with the formation of a molecular dimer. To further consolidate this, the theoretical SAXS pattern of the optimized structure of $\mathbf{K}_{\mathrm{Si}}[\mathbf{p y r}]_{2} \cdot[\mathbf{P d}(\mathbf{e d a})]_{2}$ was computed using the program $\mathrm{CRYSOL}^{30}$ from the atomic coordinates of the optimized structure. We observe that the intensity at small $\mathrm{q}$ values and the first oscillation are very well reproduced, which fully support the macrocyclic structure (Figure 4.A.).

\section{Aggregation induced by the addition of solvents : $\mathrm{CD}_{3} \mathrm{CN} \& \mathrm{D}_{2} \mathrm{O}$}

We have previously shown that in the presence of a less dissociating solvent than DMSO (such as acetonitrile) or a protic solvent, POM-based metallomacrocycles that contain positive and negative charges can aggregate through electrostatic interactions between the charged sub-units. (include reference) Here, in the presence of $\mathrm{CD}_{3} \mathrm{CN}$ or $\mathrm{D}_{2} \mathrm{O}$, the ${ }^{1} \mathrm{H}$ NMR spectrum of the POM$\mathrm{Pd}$ supramolecular system drastically broadens. Note that the final concentration should not exceed $\mathrm{c}_{\mathrm{POM}}=0.5 \mathrm{mM}$ in order to avoid partial precipitation of the solution. The two mixtures (DMSO$d_{6} / \mathrm{CD}_{3} \mathrm{CN}: 1 / 4$; DMSO- $d_{6} / \mathrm{D}_{2} \mathrm{O}: 1 / 1, \mathrm{C}_{\mathrm{POM}}=0.5 \mathrm{mM}$ ) were analyzed by SAXS (Figure 4 ) and electron microscopy (Figure 5) to characterize the overall structure of these new supramolecular architectures. In the SAXS patterns, we observe in both DMSO- $d_{6} / \mathrm{CD}_{3} \mathrm{CN}$ and DMSO- $d_{6} / \mathrm{D}_{2} \mathrm{O}$ mixtures the presence of a new peak, at large $\mathrm{q}$ values $\left(\mathrm{q}=0.35-0.5 \AA^{-1}\right)$, which are not present in the SAXS pattern of the discrete species in DMSO- $d_{6}$. These peaks correspond to specific POMPOM distances within the aggregates and indicate that they both display some internal nanostructuration. While in DMSO- $d_{6} / \mathrm{CD}_{3} \mathrm{CN}$ the peak can be deconvoluted by a single component 
centered at $\mathrm{q}=0.436 \AA^{-1}$ (corresponding to a distance $\mathrm{d}=1.44 \mathrm{~nm}$ ), 2 components are necessary to accurately fit the peak in the case of the DMSO- $\mathrm{D}_{2} \mathrm{O}$ solvent $\left(\mathrm{q}_{1}=0.376 \AA^{-1}, \mathrm{q}_{2}=0.490 \AA^{-1}\right.$ corresponding to distances $\mathrm{d}_{1}=1.67 \mathrm{~nm}$ and $\mathrm{d}_{2}=1.28 \mathrm{~nm}$ respectively, Figure $\mathrm{S} 7$ ). The larger $\mathrm{q}$ value in the presence of water reveals that the POM-POM distances are shorter than in the presence of acetonitrile.

At lower wavevectors, the signal intensity is considerably higher than that of the starting buildingblock $\mathbf{K}_{\mathrm{Si}}[\mathrm{pyr}]$ at the same POM concentration $\left(0.5 \mathrm{mM}\right.$ in DMSO- $\left.d_{6}\right)$. In DMSO- $d_{6} / \mathrm{D}_{2} \mathrm{O}(1 / 1)$ solution, at small $\mathrm{q}$ values the intensity keep increasing for $\mathrm{q} \rightarrow 0$ with a slope between $\mathrm{q}^{-1}$ and $\mathrm{q}^{-2}$ suggesting that the aggregates are anisotropic and contain (at least) one preferential orientation. Among the various models tested to fit the data, the SAXS patterns were best reproduced by using a model of almost infinite flexible cylinders of $5.4 \mathrm{~nm}$ in radius (50\% polydispersity) and a Kuhn length (i.e., average segment length of the flexible cylinder) of $15 \mathrm{~nm}$ (Figure 4). Note that the exact evaluation of the length of the cylinder (above hundreds of nanometers) is not possible with $\mathrm{q}>2 \times$ $10^{-3} \AA^{-1}$. These results were confirmed by TEM analysis (Figure 5), which shows that the aggregates appear to be ramified flexible cylinders with a cherry-branch structures with a section of 8-10 nm (slightly less than the values obtained by SAXS). The difference in the evaluation of the section between SAXS and TEM may arise from the SAXS model that does not account for the branched nature of the aggregates in solution.

In the case of DMSO- $d_{6} / \mathrm{CD}_{3} \mathrm{CN}$ mixture, the slope at low $\mathrm{q}$ is lower but the Guinier regime is never reached. TEM micrographs of the aggregates obtained by deposition of the same sample on a grid after further dilution in acetonitrile shows the formation of isotropic polydisperse assemblies (Figure 5) with a diameter comprise between $20 \mathrm{~nm}$ and $45 \mathrm{~nm}$ (Figure S8). Guided by these results, we tried to fit the SAXS pattern with various models such homogenous spheres with constant electron density or a vesicle model with a monolayer of POMS separating an interior and an exterior part filled with solvent. Both modes do not reproduce well the SAXS intensity. The faint oscillation at around $\mathrm{q}=0.08 \AA^{-1}$ together with the slowly increasing intensity at lower q suggest an inhomogeneous electron density inside a close shape. A multishell model indeed reproduces well the oscillation (Figure SXX) but further studies are required to get a more precise structure of the these assemblies.
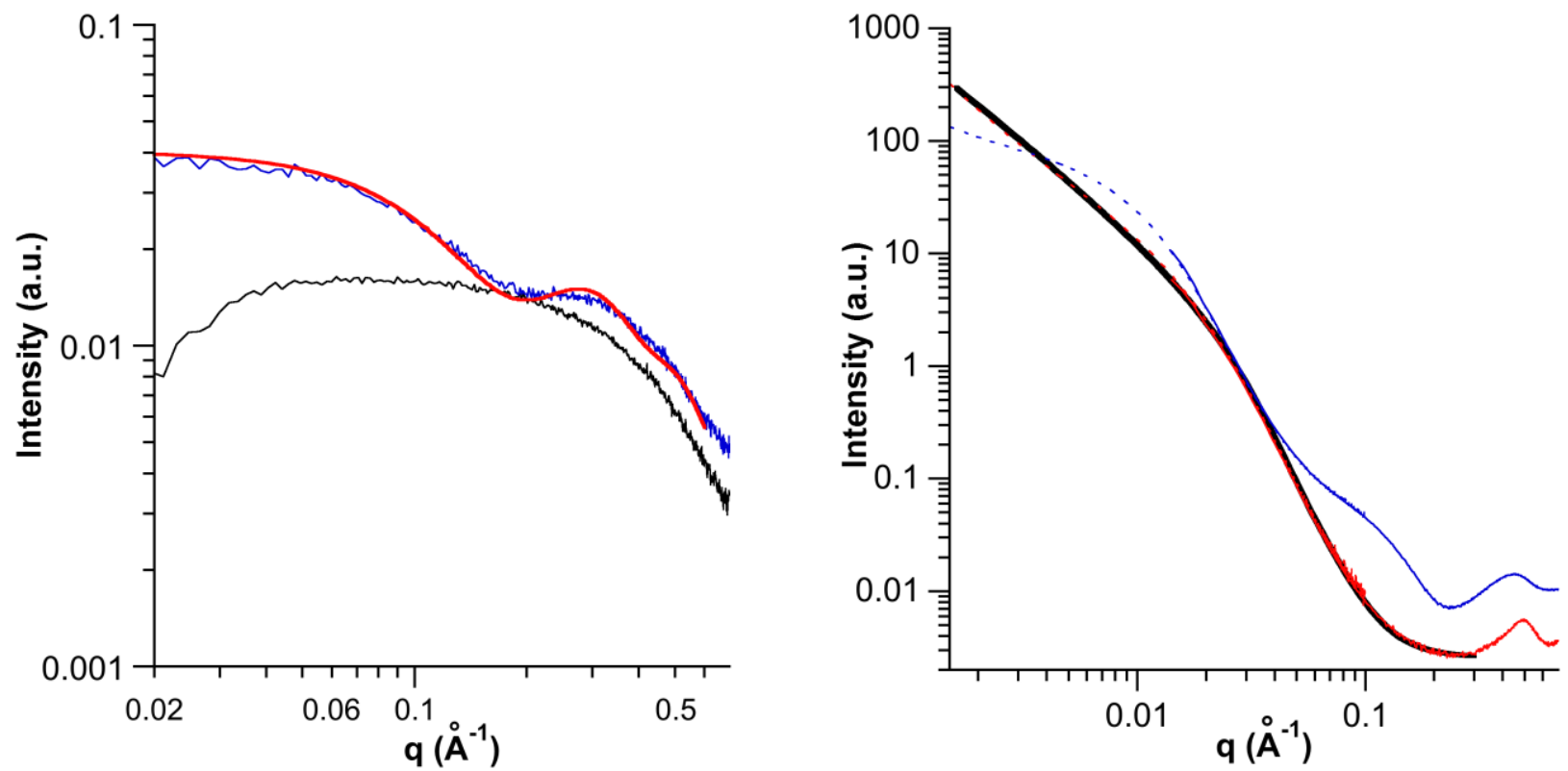

Figure 4. Left) Experimental SAXS pattern of a solution of the molecular building-block $\mathbf{K}_{\mathrm{Si}}[\mathbf{p y r}]$ (0.5 $\mathrm{mM}$ in DMSO- $\mathrm{d}_{6}$, black) and the resulting supramlecular assembly in the presence of 1.2 equiv. $\left[\mathrm{Pd}(\mathrm{eda})(\mathrm{MeCN})_{2}\right]\left(\mathrm{BF}_{4}\right)_{2}$ (blue) and computed SAXS pattern (CRYSOL) of the optimized structure of $\mathbf{K}_{\mathrm{Si}}[\mathbf{p y r}]_{2} \cdot[\mathbf{P d}(\mathbf{e d a})]_{2}$ (red). Right) Experimental SAXS pattern of a solution of the POM-Pd supramolecular assembly in $\left(\mathrm{C}_{\mathrm{POM}}=0.5 \mathrm{mM}\right)$ in DMSO- $d_{6} / \mathrm{CD}_{3} \mathrm{CN}: 1 / 4$ (blue); DMSO- 
$d_{6} / \mathrm{D}_{2} \mathrm{O}: 1 / 1$ (red) and computed SAXS pattern (SasView) of an infinite flexible cylinder, $5.4 \mathrm{~nm}$ in radius (polydispersity 50\%) and a Kuhn length of $15 \mathrm{~nm}$ (black).
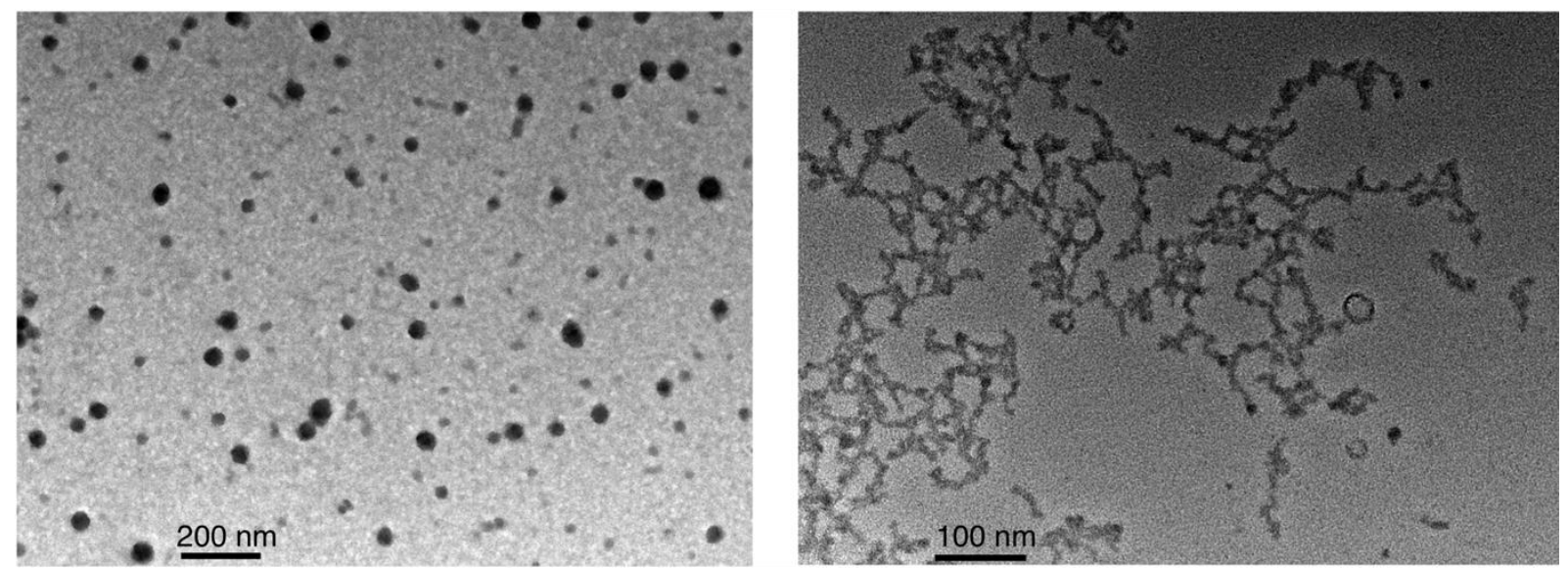

Figure 5. TEM micrograph of the POM-Pd system in $\mathrm{DMSO} / \mathrm{CD}_{3} \mathrm{CN}$ (left) and $\mathrm{DMSO} / \mathrm{D}_{2} \mathrm{O}$ (right) mixtures.

We previously observed that different types of hierarchical self-assemblies can be selectively formed according to the solvent composition as a consequence of different aggregation modes of the metallomacrocycles. In the previous study the size of the aggregates (isotropic and pseudo-1D) were much smaller than those of the current study, probably as a consequence of stronger electrostatic interactions in the current POM-Pd metallomacrocycles. The difference in the aggregation mode between $\mathrm{DMSO} / \mathrm{CD}_{3} \mathrm{CN}$ and $\mathrm{DMSO} / \mathrm{D}_{2} \mathrm{O}$ mixtures probably arise from the solvation energy of the charged species. Indeed, in the elongated branched structures, the surface to volume ratio is considerably improved. Consequently, in this aggregation mode the number of POM and $\mathrm{Pd}(\mathrm{eda})$ complexes pointing toward the solvent is much higher than in the isotropic aggregates. The cherry-branched nanostructures would then preferentially be formed in the presence of water due to improved solvation energy between the charged species and TBA with water, probably at the expense of a lower compacity compared to the isotropic particles in DMSO/MeCN mixtures.

\section{Conclusion}

We elaborated a new POM-based metallomacrocycle using a ditopic hybrid POM donor and $90^{\circ}$ metal acceptor. Using this synthetic strategy, a single discrete supramolecular species was obtained, by contrast to previous approach relying on the use of linear metal acceptors that led to the formation of mixtures of different metallomacrocycles. We observed that this new supramolecular species is able to further self assemble into different types of nanostructured hierarchical species according to the solvent composition. These complex molecular assemblies display bigger structures than the previously reported systems owing to the smaller size of the metallomacrocycle, which leads to improved electrostatic interactions. The large cherry branched structures displaying large size and close POM-POM distances hold great promise as semiconducting materials for the elaboration of neuromorphic networks.

Ackowledgements:

We acknowledge SOLEIL for provision of synchrotron radiation facilities and we would like to thank Thomas Bizien for assistance in using beamline SWING.

SAXS methods: 
The small angle X-ray scattering data were acquired on the SWING beamline at syncrhotron SOLEIL (Saint Aubin, France). The nanocrystal dispersions were loaded in glass capillaries with an outside diameter between 1 and $1.5 \mathrm{~mm}$ and glass walls of $0,01 \mathrm{~mm}$ (WJM-Glas, Germany). The energy of the X-ray beam was $12 \mathrm{keV}$. The scattered X-ray were detected using an EIGER 4M detector situated at 6.231 or $0.517 \mathrm{~m}$ distance from the sample. 10 images were taken with a typical acquisition time of $250 \mathrm{~ms}$ and averaged to increase the signal to noise ratio. The SAXS intensity was normalized using beamline specific procedures and radially averaged using FOXTROT 3.4.1.

\section{References}

1. Robinson, M. E.; Nazemi, A.; Lunn, D. J.; Hayward, D. W.; Boott, C. E.; Hsiao, M. S.; Harniman, R. L.; Davis, S. A.; Whittell, G. R.; Richardson, R. M.; De Cola, L.; Manners, I., Dimensional Control and Morphological Transformations of Supramolecular Polymeric Nanofibers Based on Cofacially-Stacked Planar Amphiphilic Platinum(II) Complexes. ACS Nano 2017, 11 (9), 9162-9175.

2. Lescop, C., Coordination-Driven Syntheses of Compact Supramolecular Metallacycles toward Extended Metallo-organic Stacked Supramolecular Assemblies. Acc. Chem. Res. 2017, 50 (4), 885-894.

3. Chan, M. H. Y.; Ng, M.; Leung, S. Y. L.; Lam, W. H.; Yam, V. W. W., Synthesis of Luminescent Platinum(II) 2,6-Bis-(N-dodecylbenzimidazol-2 '-yl)pyridine Foldamers and Their Supramolecular Assembly and Metallogel Formation. J. Am. Chem. Soc. 2017, 139 (25), 86398645.

4. Jiang, H. J.; Zhang, L.; Chen, J.; Liu, M. H., Hierarchical Self-Assembly of a Porphyrin into Chiral Macroscopic Flowers with Superhydrophobic and Enantioselective Property. ACS Nano 2017, 11 (12), 12453-12460.

5. Rest, C.; Kandanelli, R.; Fernandez, G., Strategies to create hierarchical self-assembled structures via cooperative non-covalent interactions. Chem. Soc. Rev. 2015, 44 (8), 2543-2572.

6. Mariani, G.; Moldenhauer, D.; Schweins, R.; Gröhn, F., Elucidating Electrostatic SelfAssembly: Molecular Parameters as Key to Thermodynamics and Nanoparticle Shape. J. Am. Chem. Soc. 2016, 138 (4), 1280-1293.

7. Kim, Y.; Li, W.; Shin, S.; Lee, M., Development of Toroidal Nanostructures by SelfAssembly: Rational Designs and Applications. Acc. Chem. Res. 2013, 46 (12), 2888-2897.

8. Yu, G. C.; Jie, K. C.; Huang, F. H., Supramolecular Amphiphiles Based on Host-Guest Molecular Recognition Motifs. Chem. Rev. 2015, 115 (15), 7240-7303.

9. Sun, Y.; Chen, C. Y.; Stang, P. J., Soft Materials with Diverse Suprastructures via the SelfAssembly of Metal-Organic Complexes. Acc. Chem. Res. 2019, 52 (3), 802-817.

10. Yan, Y.; Huang, J. B., Hierarchical assemblies of coordination supramolecules. Coord. Chem. Rev. 2010, 254 (9-10), 1072-1080.

11. Yamada, T.; Otsubo, K.; Makiura, R.; Kitagawa, H., Designer coordination polymers: dimensional crossover architectures and proton conduction. Chem. Soc. Rev. 2013, 42 (16), 66556669.

12. Chakrabarty, R.; Mukherjee, P. S.; Stang, P. J., Supramolecular Coordination: SelfAssembly of Finite Two- and Three-Dimensional Ensembles. Chem. Rev. 2011, 111 (11), 68106918.

13. Herasymchuk, K.; Miller, J. J.; MacNeil, G. A.; Sergeenko, A. S.; McKearney, D.; Goeb, S.; Salle, M.; Leznoff, D. B.; Storr, T., Coordination-driven assembly of a supramolecular square and oxidation to a tetra-ligand radical species. Chem. Commun. 2019, 55 (43), 6082-6085.

14. Bivaud, S.; Balandier, J. Y.; Chas, M.; Allain, M.; Goeb, S.; Salle, M., A Metal-Directed Self-Assembled Electroactive Cage with Bis(pyrrolo)tetrathiafulvalene (BPTTF) Side Walls. J. Am. Chem. Soc. 2012, 134 (29), 11968-11970. 
15. Tominaga, M.; Suzuki, K.; Kawano, M.; Kusukawa, T.; Ozeki, T.; Sakamoto, S.; Yamaguchi, K.; Fujita, M., Finite, spherical coordination networks that self-organize from 36 small components. Angew. Chem., Int. Ed. 2004, 43 (42), 5621-5625.

16. Ji, Y. C.; Huang, L. J.; Hu, J.; Streb, C.; Song, Y. F., Polyoxometalate-functionalized nanocarbon materials for energy conversion, energy storage and sensor systems. Energy Environ. Sci. 2015, 8 (3), 776-789.

17. Miras, H. N.; Yan, J.; Long, D. L.; Cronin, L., Engineering polyoxometalates with emergent properties. Chem. Soc. Rev. 2012, 41 (22), 7403-30.

18. Li, B.; Li, W.; Li, H. L.; Wu, L. X., Ionic Complexes of Metal Oxide Clusters for Versatile Self Assemblies. Acc. Chem. Res. 2017, 50 (6), 1391-1399.

19. Izzet, G.; Volatron, F.; Proust, A., Tailor-made Covalent Organic-Inorganic Polyoxometalate Hybrids: Versatile Platforms for the Elaboration of Functional Molecular Architectures. Chem. Rec. 2017, 17 (2), 250-266.

20. Proust, A.; Matt, B.; Villanneau, R.; Guillemot, G.; Gouzerh, P.; Izzet, G., Functionalization and post-functionalization: a step towards polyoxometalate-based materials. Chem. Soc. Rev. 2012, 41 (22), 7605-7622.

21. Piot, M.; Abecassis, B.; Brouri, D.; Troufflard, C.; Proust, A.; Izzet, G., Control of the hierarchical self-assembly of polyoxometalate-based metallomacrocycles by redox trigger and solvent composition. Proc. Natl. Acad. Sci. U. S. A. 2018, 115 (36), 8895-8900.

22. Izzet, G.; Abécassis, B.; Brouri, D.; Piot, M.; Matt, B.; Serapian, S. A.; Bo, C.; Proust, A., Hierarchical Self-Assembly of Polyoxometalate-Based Hybrids Driven by Metal Coordination and Electrostatic Interactions: From Discrete Supramolecular Species to Dense Monodisperse Nanoparticles. J. Am. Chem. Soc. 2016, 138 (15), 5093-5099.

23. Izzet, G.; Macdonell, A.; Rinfray, C.; Piot, M.; Renaudineau, S.; Derat, E.; Abécassis, B.; Afonso, C.; Proust, A., Metal-Directed Self-Assembly of a Polyoxometalate-Based Molecular Triangle: Using Powerful Analytical Tools to Probe the Chemical Structure of Complex Supramolecular Assemblies. Chem. Eur. J. 2015, 21 (52), 19010-19015.

24. Piot, M.; Hupin, S.; Lavanan, H.; Afonso, C.; Bouteiller, L.; Proust, A.; Izzet, G., Charge Effect on the Formation of Polyoxometalate-Based Supramolecular Polygons Driven by Metal Coordination. Inorg. Chem. 2017, 56 (14), 8490-8496.

25. Grimme, S.; Bannwarth, C.; Shushkov, P., A Robust and Accurate Tight-Binding Quantum Chemical Method for Structures, Vibrational Frequencies, and Noncovalent Interactions of Large Molecular Systems Parametrized for All spd-Block Elements $(\mathrm{Z}=1-86)$. J. Chem. Theory Comput. 2017, 13 (5), 1989-2009.

26. Bannwarth, C.; Ehlert, S.; Grimme, S., GFN2-xTB-An Accurate and Broadly Parametrized Self-Consistent Tight-Binding Quantum Chemical Method with Multipole Electrostatics and Density-Dependent Dispersion Contributions. J. Chem. Theory Comput. 2019, 15 (3), 1652-1671.

27. Nyman, M., Small-angle X-ray scattering to determine solution speciation of metal-oxo clusters. Coord. Chem. Rev. 2017, 352, 461-472.

28. Li, M.; Wang, W. Y.; Yin, P. C., A General Approach to Access Morphologies of Polyoxometalates in Solution by Using SAXS: An Ab Initio Modeling Protocol. Chem. Eur. J. 2018, 24 (25), 6639-6644.

29. Wu, Y. L.; Shi, R. F.; Wu, Y. L.; Holcroft, J. M.; Liu, Z. C.; Frasconi, M.; Wasielewski, M. R.; Li, H.; Stoddart, J. F., Complexation of Polyoxometalates with Cyclodextrins. J. Am. Chem. Soc. 2015, 137 (12), 4111-4118.

30. Svergun, D.; Barberato, C.; Koch, M. H. J., CRYSOL - A program to evaluate X-ray solution scattering of biological macromolecules from atomic coordinates. J. Appl. Crystallogr. 1995, 28, 768-773. 